\title{
CAMBIO SOCIAL Y SOLIDARIDAD ENTRE GENERACIONES DE MUJERES ${ }^{1}$
}

\author{
CONSTANZA TOBÍO \\ Universidad Carlos III de Madrid
}

La incorporación a la actividad laboral de las mujeres en España se produce tarde en comparación con otros países europeos y occidentales. Sólo a partir de los años ochenta se impone entre las generaciones más jóvenes una pauta moderna caracterizada por el hecho de que la mayoría de las mujeres acceden al mercado de trabajo y permanecen en él a lo largo de toda la vida ${ }^{2}$. Ello supone que las madres de hoy pertenecen a las primeras generaciones femeninas mayoritariamente activas, mientras que sus madres forman parte de las últimas en las que la dedicación al mundo doméstico era la ocupación habitual de las mujeres.

1. Este texto se basa en datos y resultados de cuatro proyectos de investigación diferentes: «Estrategias de compatibilización familia-empleo. España años noventa» subvencionado por el Instituto de la Mujer (convocatoria 28-3-94); "Las Familias Monoparentales en España» realizada en el marco del convenio Ministerio de Asuntos Sociales-Universidad Carlos III de Madrid 1996-97); "Obstáculos para la incorporación de las mujeres a la actividad laboral en la periferia rural y metropolitana de Madrid» realizada en el marco del convenio entre la Dirección General de la Mujer de la Comunidad de Madrid y la Universidad Carlos III de Madrid (1996-98); "Análisis cuantitativo de las estrategias de compatibilización familia-empleo en España", investigación realizada en el marco del Programa Sectorial de Estudios del Género y de las Mujeres del III Plan Nacional de Investigación. Una primera versión de este trabajo se presentó en las XII Jornadas de Investigación "Ciudadanía y Género: revisiones desde el ámbito privado», organizadas por el Instituto Universitario de Estudios de la Mujer de la Universidad Autónoma de Madrid del 11-13 de marzo 1998, y en las Jornadas sobre «Mujeres Mayores en la Europa del siglo XXI: de la invisibilidad al protagonismo» organizadas por el Instituto Universitario de Estudios de la Mujer de la Universidad Autónoma de Madrid y la Dirección General de la Mujer de la Comunidad de Madrid el 16-17 de noviembre 2000 .

2. En 1975 sólo el 25,65\% de las mujeres de 35-39 años estaban en el mercado de trabajo, cifra que aumenta a un $60,7 \%$ en 1995 y a un $84 \%$ en 2005 según una proyección realizada por Juan Antonio Fernández Cordón a partir de una serie homogeneizada de datos de la Encuesta de Población Activa para 1975 elaborada por Carmen de Miguel (Tobío C., Arteta, E. y Fernández Cordón, J. A.: "Estrategias de compatibilización familia-empleo. España años noventa», Departamento de Humanidades, Ciencia Política y Sociología, Universidad Carlos III de Madrid/Instituto de la Mujer, Informe de Investigación, 1996). La misma pauta se observa en los grupos quinquenales anteriores y posteriores que coinciden con los años de más elevada fecundidad.

Feminismo/s, 2, diciembre 2003, pp. 153-166 
Las madres de hoy se perciben como una generación de transición, muy diferente de sus propias madres, pero también de sus hijas cuyo futuro culminará, creen, el camino por ellas iniciado. Las abuelas representan a la mujer de antes, cuya seguridad se asocia a la posición en la familia, dependiente siempre de un varón. Su espacio es el hogar, su ocupación la reproducción y mantenimiento de los miembros de la familia, y su virtud típica el sacrificio. Dependencia y seguridad son los dos rasgos característicos y complementarios que permiten entender la lógica que subyace a su situación. Las madres de hoy perciben su propia situación como diferente. Las reglas del juego han cambiado, en primer lugar porque la familia no es ya para las mujeres la institución segura para toda la vida que era antes. La seguridad -en sentido amplio, económico, social, personal-ya no puede vincularse, el menos en exclusividad, a la pertenencia a una familia sino que se diversifica, cobrando importancia creciente la propia seguridad individual a través del trabajo y la autonomía económica que éste conlleva. Trabajar representa para las madres de hoy el factor clave en la búsqueda de una independencia individual y la construcción de una nueva identidad. Sin embargo, las dificultades y los obstáculos son numerosos. Se perciben como un grupo social pionero que ha iniciado un proceso todavía no culminado en el que lo que no será (o no desean que sea) está más definido que el objetivo final. Éste se vislumbra a través de la proyección discursiva de las madres trabajadoras en sus hijas que se representan como una visión gratificante de sí mismas despojadas de dudas y vacilaciones, como la antítesis de las abuelas.

Diversos factores de tipo coyuntural y estructural confieren a las abuelas un papel fundamental en la generalización y normalización de la actividad laboral femenina. En un contexto de escasas políticas sociales orientadas a la compatibilización familia-empleo, así como de reducida importancia del trabajo a tiempo parcial, el papel de las abuelas que se hacen cargo del cuidado de los hijos de las madres trabajadoras constituye una forma de solidaridad entre generaciones que está haciendo posible el cambio en la posición económica y social de las mujeres. Se produce así la paradoja de que la asunción del rol tradicional de madre por parte de las abuelas está haciendo posible la transformación de los viejos roles de género. Se trata de una estrategia provisional, según las madres trabajadoras de hoy, de una solución de urgencia para una generación de transición que está afrontando nuevos problemas para los que no hay todavía una respuesta que constituya un modelo de futuro.

Este trabajo se basa en los discursos ${ }^{3}$ de las madres de hoy acerca de la generación anterior -cómo eran y cómo vivían sus propias madres, las abuelas de hoy- y la generación posterior, como serán y cómo vivirán sus hijas mañana.

3. En total, en las tres investigaciones de las que proceden los resultados que aquí se presentan se realizaron dieciocho grupos de discusión y setenta y tres entrevistas en profundidad en las ciudades de Madrid, Barcelona, Valencia, Bilbao, Getafe y Parla, así como en las comarcas del MISSEM y Las Vegas en la Comunidad de Madrid. En todos los casos se entrevistó a mujeres a partir de las siguientes variables de segmentación: edad, clase social, actividad laboral y situación familiar. El trabajo de campo se hizo entre 1995 y 1999. 
En la segunda parte, se trata la ayuda efectiva que prestan las abuelas a sus hijas que trabajan y son madres. En la última parte se aborda el sistema de intercambios entre generaciones a partir de la hipótesis de que asistimos al final de un ciclo ya que el cambio social que protagonizan las madres de hoy libera de la exigencia de reciprocidad.

\section{LAS ABUELAS, MADRES DE AYER}

Las referencias a la generación de las abuelas remiten a un modelo de mujer que parece mucho más alejado en el tiempo que los treinta o cuarenta años atrás a los que normalmente se refieren. Las palabras más repetidas son «sin elección», "encierro", "miedo», "sacrificio» y "aguantar».

Madre era antes sinónimo de ama de casa, no había otras opciones para las mujeres con hijos. El destino de las madres era cuidar de la familia y los hijos.

«...por ejemplo, mi abuela era una mujer que toda la vida cuidando hijos $[\ldots]$ antes no te dejaban estudiar, antes servías solamente para limpiar.» (EP ${ }^{4}$ Madrid, monoparental, clase media, trabaja)

Incluso si trabajaban fuera del hogar, lo cual era frecuente en explotaciones agrícolas familiares, o como jornaleras, ese trabajo y su remuneración era una aportación indiferenciada a la economía familiar, no demasiado diferente del trabajo doméstico. No era, como ahora, un trabajo individual que las mujeres perciben como base y expresión de su propia autonomía.

«El objetivo del trabajo era totalmente distinto. Tú ahora trabajas de

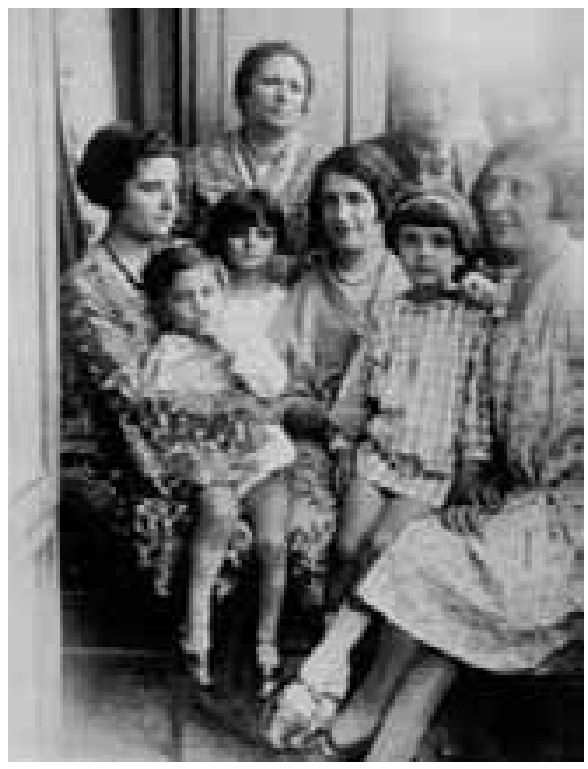
alguna manera para ti... para salir tú adelante. Y antes era más dentro del mundo de la familia. Si trabajabas en el campo, por ejemplo, era dentro de la economía familiar y si estabas en la ciudad un tanto por ciento muy elevado de lo que ganabas lo aportabas para casa... Yo creo que ahora la mujer que trabaja, trabaja para ella. Ya no es tan primaria la familia, se hace más secundaria.» (GD ${ }^{5}$ Bilbao, viven en pareja o casadas, con hijos, clase baja, trabajan, 20-29 años)

Las mujeres de antes estaban "metidas en casa", su círculo de relaciones sociales se limitaba generalmente a la familia y ese "estar fuera del mundo» se asociaba a un no saber, no entender, que restaba valor a sus juicios.

4. Entrevista en profundidad.

5. Grupo de discusión. 
«Era normal que dijera [el padre de la entrevistada a la madre]: "Tú no sabes porque no estás en el mundo del trabajo"... entonces no era desprecio, era que como que no estaba en ese mundo no podía opinar, no estaba ahí, no podía saber cómo se cocían las cosa.» (EP Madrid, monoparental, clase media, trabaja)

Se dice que las mujeres antes tenían miedo a hablar, a decir según qué cosas al marido, a perder su sustento económico. Había una tendencia al ocultamiento de los conflictos, incluso del maltrato de los hombres. Todo ello configuraba una forma de ser típicamente femenina: el sacrificio. Es la madre que sólo existe para los demás, cuya razón de ser es el bienestar de la familia.

"Yo mi referencia materna es sacrificio total y absoluto, la última que come, como los desperdicios, es la que limpia, limpia los culos a mi padre...» (GD Bilbao, monoparentales, clase baja, trabajan)

Esa capacidad de sacrificio, casi inhumana por extrema, produce una cierta admiración, quizá porque las mujeres de hoy se reconocen incapaces de un comportamiento así, quizá también porque ese estoicismo era una forma de poder, tal como trasluce la expresión "poder de sacrificio».

«Yo admiro a la mujer de antes [...] por el poder de sacrificio que tenía.» (GD Bilbao, monoparentales, clase baja, trabajan)

Todo ello se resume en la palabra que expresa el cambio: "aguantar». Las mujeres de antes aguantaban en general, como actitud vital y eso es lo que las diferencia de las de hoy, que ya no aguantan, incluso se llega a decir que quizá aguantan demasiado poco.

«...en la época de mi madre, peor en la de mi abuela, pues se tenía que aguantar mucho, se tenía que tolerar muchas cosas.» (GD Barcelona, monoparentales, clase alta, no trabajan)

«La mujer tenía una capacidad de aguante, cosa que ahora mismo ni aguantamos a los niños, ni aguantamos que los hombres, tu marido te diga « $U h$ !» porque automáticamente ya estás con el divorcio en la mano.» (GD Bilbao, monoparentales, clase baja, trabajan)

Aparecen, sin embargo, algunas referencias más positivas a la situación anterior, que giran en torno a la idea de "tranquilidad» $y$ "tener tiempo». Se dice que antes las mujeres tenían más tiempo para todo, incluso para sí mismas, que podían hacer más cosas y más intensamente. El alejamiento del mundo del trabajo y de la supervivencia económica les permitía concentrar sus intereses, desarrollar las relaciones personales más en profundidad con los más próximos y despreocuparse del mundo exterior al hogar.

«Tenía más tiempo para todo, para todo en general [...] antes quizá estabas más en casa, tenías menos círculos, ahora por trabajos, y depende de qué trabajos, contactas con más personas, pero contactas de vista, no te da tiempo a congeniar con ellas [...] evidentemente tenías más tiempo para...» EP Madrid, monoparental, clase media, trabaja) 
«En general, supongo que vivieron fatal a muchos niveles ¿̨no? Pero tenían otra tranquilidad, no tenían el estrés continuo que tenemos nosotras.» (EP Madrid, monoparental, clase media, trabaja)

Hay una cierta añoranza de un pasado en que la vida limitada de las mujeres, la escasez de opciones se traducían en tranquilidad a través de la aceptación de su situación. Nostalgia, en definitiva de la dependencia y de su contraparti$\mathrm{da}$, la seguridad, desde la perspectiva actual en que la variedad de opciones y la capacidad de elegir abren la puerta al miedo y a la angustia que el ejercicio de la autonomía generan. La fantasía de regresión a un pasado más simple se articula con la crítica de la sociedad de consumo a la que subyace una cierta idea de trampa en la que quizá caen las mujeres de hoy, pues se preguntan si su entrada en el mercado de trabajo no responde en realidad a la lógica dominante del consumo creciente. Se habla de falsas necesidades, de necesidades ficticias que no constituyen lo básico, meramente superfluas. La alimentación, por ejemplo, era más sana y de más calidad antes, aunque hoy hay una mayor cantidad y variedad de productos alimenticios.

"Yo comía un cocido, comía judías, comía unas lentejas y comía una patata guisada, igual que me las puedo comer ahora, sólo que a lo mejor yo en el frigorífico tengo media docena de yogures, media docena de flanes, dos medias libras de chocolate, y antes no las teníamos, pero en cuanto a comida...» (GD Comarca de las VegasMadrid, mujeres que viven en pareja o casadas, con hijos, trabajan, más de 40 años)

En resumen, la situación anterior se representa como la dependencia, con múltiples desventajas de falta de autonomía y de libertad de opciones, así como de escasa valoración de su limitada función social, aunque también con algunas ventajas ya que esos mismos factores negativos situaban a las mujeres al margen de problemas que hoy tienen que abordar y resolver individualmente.

\section{LA GENERACIÓN PUENTE: MADRES Y TRABAJADORAS}

Las mujeres entrevistadas, madres trabajadoras generalmente entre 20 y 50 años se perciben a sí mismas como muy diferentes de sus madres. La mayoría son pioneras generacionales, no reproducen el comportamiento de sus madres, sino que en la mayoría de los casos son las primeras de sus respectivos linajes femeninos en adentrarse en el mundo laboral y en hacerlo con vocación de continuidad, como revela el hecho de trabajar y tener hijos. Han salido de sus casas, han estudiado, se han incorporado al trabajo, hablan abiertamente, controlan el número y el momento de tener los hijos, entablan relaciones más iguales y «puras» con los hombres en el sentido al que se refiere Giddens que no tiene nada que ver con la pureza sexual sino con «una situación en la que una relación social se establece por iniciativa propia, asumiendo lo que se puede derivar para cada persona de una asociación sostenida con otra y que se prosigue sólo en la medida en que se juzga por ambas partes que esta asociación produce la suficiente satisfacción para cada individuo» ${ }^{6}$.

6. GDdens, Anthony: La transformación de la intimidad. Sexualidad, amor y erotismo en las sociedades modernas, Cátedra, Madrid, 1995, pp. 60-61. 


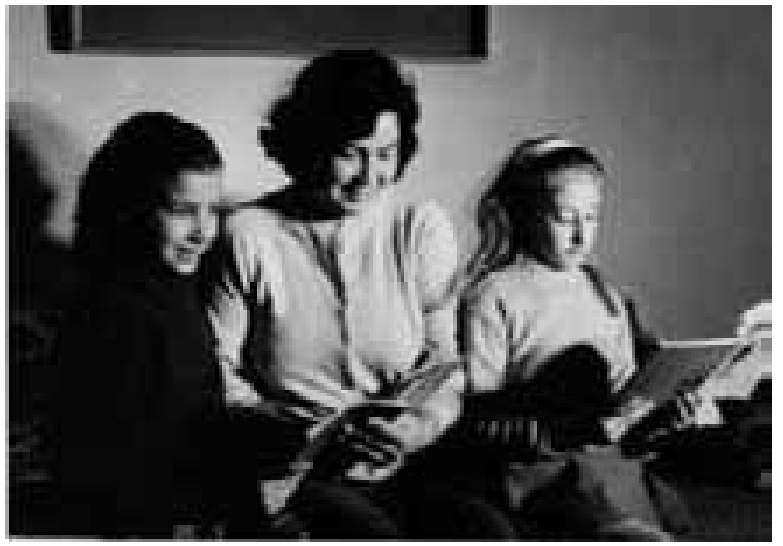

El acceso al trabajo remunerado aparece como el factor clave que desencadena el cambio en la posición de las mujeres en la sociedad. Las razones por las que las mujeres hoy desean trabajar, incluso si son madres, son múltiples: objetivas y subjetivas, individuales y familiares, económicas y sociales, por estrategia individual y determinación social, por necesidad y por deseo. El trabajo es a la vez el elemento principal en que se sustenta la autonomía, independencia y seguridad de las mujeres y la actividad en la que más claramente ésta se realiza y proyecta.

"Yo creo que es fundamental el hecho de tener independencia económica [...] ese sí que me parece un cambio fundamental [...] yo creo que es el cambio más importante, es el que te permite todo, es el que te permite hacer tu vida.» (GD Madrid, monoparentales, clase alta, trabajan)

«Te da más seguridad [el trabajo], ya no económica, si no...» (GD Madrid, viven en pareja o casadas, con hijos, clase media, trabajan, 30-39 años )

«El que seas independiente económicamente te da seguridad.» (EP Valencia, casada, con hijos, clase media, trabaja, 40-49)

«Mi marido es abogado y odia el juzgado. En cambio a mí me encanta. Yo disfruto estando en el juzgado, yendo a los juicios.» (EP Madrid, casada, con hijos, clase alta, trabaja, 30-39 años)

«Si me toca una lotería de quinientos millones yo no dejo de trabajar.» (GD Madrid, viven en pareja o casadas, con hijos, clase baja, trabajan, 20-29 años)

Las mujeres han transformado su rol tradicional de amas de casa incorporándose al trabajo remunerado, sin embargo no han abandonado en realidad el rol anterior sino que han añadido a éste el nuevo. Superponen las nuevas responsabilidades laborales a las viejas responsabilidades domésticas. Perciben que las mujeres son libres para desarrollar nuevas actividades, pero no para abandonar su papel en la familia.

"Ah, jmuy bien! Trabaja aquí, allí, donde tú quieras. Haz vida social, haz vida cultural, haz lo que tú quieras, pero el otro papel [el de ama de casa] no lo dejes.» (GD Barcelona, viven en pareja o casadas, clase media, trabajan, 30-39 años)

Ésta parece ser, efectivamente, la percepción social mayoritaria tal como se deduce de algunos datos de encuesta, aunque se observan cambios en los últi- 
mos años. Una encuesta de 1983 a madres trabajadoras daba como resultado que el $86 \%$ de las entrevistadas afirmaba que «la mujer puede trabajar siempre que lo haga compatible con el cuidado de la familia ${ }^{7}$. En 1990 una encuesta a la población española arrojaba el dato de que un $45 \%$ de los entrevistados afirmaba que el mejor modelo de familia era aquel en que tanto el hombre como la mujer trabajan fuera de casa y se reparten las tareas del hogar y el cuidado de los hijos, porcentaje que en 1994 aumentaba al 53\% ${ }^{8}$. El avance ideológico no es, sin embargo, paralelo a los comportamientos: según el Eurobarómetro de 1991 sobre la familia los hombres españoles son los que menos colaboran en las tareas domésticas en comparación con los de los restantes países europeos, con la excepción de Irlanda9.

Sin embargo, al tiempo que hay una queja por la carga escasamente compartida de la responsabilidad doméstica, los discursos analizados reflejan grandes dudas en cuanto a la posibilidad de que los hombres puedan asumir la responsabilidad del funcionamiento del hogar, aunque sí la ayuda en tareas concretas. Quizá hay una cierta resistencia a abandonar funciones de carácter directivo, aunque sea en el ámbito subalterno de lo doméstico.

«...pero hay una persona que dirige y pienso que la que realmente tiene dotes de mando en este caso...» (EP Valencia, casada, con hijos, clase alta, trabaja, 40-49 años)

Hay también un modelo de orden doméstico y familiar que permanece presente como referente positivo interiorizado. A pesar de los diversos adelantos relacionados con la mecanización de las tareas domésticas, los modos tradicionales de hacer alcanzan todavía la máxima valoración, en especial en lo que se refiere a la comida que constituye la tarea doméstica principal de las que todavía se realizan en el hogar. Permanece todavía en el imaginario colectivo, fortalecido por la literatura popular sobre hogar, cocina y decoración, una concepción de la vida familiar y del orden doméstico de carácter marcadamente tradicional. El ideal, que se llega a explicitar en ocasiones, parece ser mantener a la vez una casa como la de las madres o las abuelas y una dedicación profesional activa, ser quizá como las mujeres de antes en el hogar y como los hombres en el trabajo.

"Estás trabajando y quieres que tu casa esté como si estuvieses [en ella todo el día] porque eso yo creo que nos pasa al $95 \%$ de las mujeres que estamos trabajando, quieres tener la casa como si estuvieses ahí.» (EP Madrid, casada, con hijos, clase baja, trabaja, 30-39 años)

El efecto de la superposición entre el trabajo laboral y el doméstico es el cansancio, el agotamiento, a veces incluso la sensación de que han caído en

7. Martínez Quintana, M.V.: Mujer, trabajo y maternidad. Problemas y alternativas de las madres que trabajan, Instituto de la Mujer, Ministerio de Asuntos Sociales, Madrid, 1992, p. 28.

8. CRuz Cantero, P.: Percepción social de la familia en España, Centro de Investigaciones Sociológicas, 1995 , p. 56.

9. Ibíd., p. 55. 
una trampa, de que no vale la pena el esfuerzo. No sólo el cansancio físico sino el psíquico ya que la responsabilidad doméstica se caracteriza porque está siempre presente, nunca abandona a quien la asume. Se habla de estar viviendo "una situación imposible», de que trabajar y ser madre a la vez no es posible, dicen las madres trabajadoras.

"No puedes ser ama de casa, madre y además trabajar; es que yo no lo concibo.» (GD Madrid, viven en pareja o casadas, con hijos, clase alta, trabajan, 40-49 años)

Las referencias a estar viviendo algo que es imposible son probablemente una forma de reflejar un vivir al día, solucionando como se puede los problemas $y$ las situaciones del momento sin que haya un modelo ya establecido que sirva de soporte y orientación a su propia situación vital. La mera extrapolación de la situación del presente no conduce a una resolución del problema sino que hace más palpable que las soluciones actuales no pueden ser más que provisionales. Hay una percepción de pertenencia a una generación de transición que es la que encarna más duramente el cambio, representada por las madres trabajadoras de hoy. Las trayectorias vitales que conducen a la situación actual son de dos tipos: unas fueron educadas para ser amas de casa, lo cual es un lastre hoy para desenvolverse en el mundo profesional, otras para la vida profesional, encontrándose después las dificultades añadidas que para una mujer supone ser madre.

«No podíamos imaginar que seríamos mujeres que trabajaríamos.» (GD Madrid, viven en pareja o casadas, con hijos, clase baja, trabajan, 20-29 años)

"La carrera que quisiera, pero la carrera, cinco años, por supuesto... $O$ sea no me daban opción [los padres]. Y entonces de repente, pues me han educado para trabajar... entro en una empresa ... ipum, pum, pum! Llego, me caso, tengo un niño... ocurren cosas de éstas: «Mami, ven que el niño...» [Dice la madre] "¡Qué mal! ¡Qué mal! Ese niño... yo no sé... las mujeres de hoy en día llevan una vida...» Y digo yo: "iSi me habéis educado para esto! ¿Y cómo ahora me vais a criticar?» (GD Madrid, viven en pareja o casadas, con hijos, clase media, trabajan, 30-39 años)

Se perciben a sí mismas como una generación intermedia, "sandwich», entre un pasado representado por sus madres y un futuro en el que la nueva posición de las mujeres en la sociedad habrá sido asumida como normalidad. Ellas son en muchos de sus comportamientos (estudiar, trabajar, separarse) las primeras en hacerlo, lo cual tiene un coste tanto en términos de aceptación social como de soluciones prácticas a nuevas necesidades.

"...y nosotras estamos en el intermedio, nosotras yo digo que estamos como en los sandwiches, de pasar de nuestras madres de la mentalidad de «hacer las camitas porque el nene no puede tocar la sábana porque viene papá y le llama mariquita» a tener hijos e intentar que no les pase lo que nos ha pasado a nosotras.» GD Bilbao, monoparentales, clase baja, trabajan)

"Yo creo que estamos en una situación totalmente intermedia, totalmente intermedia.» (GD Madrid, monoparentales, clase alta, trabajan) 


\section{LAS HIJAS Y EL FUTURO}

Las hijas representan la continuidad del proceso que las madres trabajadoras de hoy iniciaron, dan sentido a un recorrido cuyo objetivos no alcanzarán seguramente más que a través de lo que transmiten a las jóvenes. Hay una fuerte proyección de las mujeres del presente en las del futuro. Ven a sus propias hijas, y a las chicas jóvenes en general, parecidas a ellas mismas pero mejoradas, más seguras, más fuertes, más preparadas. Lo que ellas no llegaron a conseguir o aquello que les costó tanto esfuerzo lo conseguirán, creen, con mucha más facilidad.

"Yo pienso que mi hija se va a comer el mundo y todas las mujeres se van a comer el mundo, de hecho lo estamos haciendo porque hemos adelantado en unos años barbaridades y eso tiene que seguir hacia delante.» (EP Bilbao, monoparental, clase alta, trabaja)

La idea central que intentan transmitirle a sus hijas es que lo principal, lo básico es su propia autonomía individual concretada en su capacidad para mantenerse a sí mismas. Ello es lo que les permitirá no necesitar a un hombre que las mantenga, situación negativa en sí, además de sumamente insegura hoy. Lo más importante para una mujer es ahora esa autonomía básica individual centrada en el trabajo. El matrimonio y la familia aparecen no como un alternativa sino como algo más que se añade a lo anterior y puede darse o no darse. Es decir, el hombre ya no es un «destino» para la mujer, ni el matrimonio una "vocación", sino un aspecto de su vida más asociado a lo emocional que a la supervivencia, ni siquiera, por tanto, el primero y más importante. Ello se concreta en la idea de que el trabajo remunerado va a ser cada vez más en el futuro un hecho, un dato, no se va a poder elegir ya que todas van a trabajar, lo que sí se podrá elegir es la familia y los hijos.

"Lo que van a elegir es entre casarse y no casarse; no pueden elegir entre trabajar y no trabajar.» (GD Madrid viven en pareja o casadas, con hijos, clase alta, trabajan, 40-49 años)

Subyace a los diferentes discursos una visión algo catastrofista en relación con la familia y a los hijos, a la vez que una visión magnificada de una mujer poderosa -que no va a aceptar lo que ellas aceptaron- que introduce algunos matices nuevos en su percepción de sí mismas y de su situación vital y posición en la sociedad. Aparece así una ambivalencia entre un modelo nuevo de mujer que resume las características de autonomía e independencia en que les gusta reconocerse y el temor a la pérdida de un viejo papel, la madre del hogar, así como un cierto resentimiento, quizá vengativo, que se concreta en una predicción catastrófica: las mujeres ya no tendrán hijos.

«- ... [en el futuro] la mujer-hombre, en fin algo diferente.

- Desde luego no va a tener hijos, no va a ir detrás, no va a poner el mantel planchado... todo eso.

$[\ldots]$ 
-Porque no me gustaría que se perdiera el hogar, el núcleo [...] porque es que está hablando de la mujer, pero es que los hijos de esa mujer serán los padres del mañana. Entonces no me gustaría que, que todo fuera una sociedad artificial [...] ¡La sociedad se basa en la familia!

$[\ldots]$

-Ahora, eso del futuro de tener hijos, lo tienen muy difícil.

$[\ldots]$

-Cada muchos matrimonios tendrá uno hijos.» (GD Madrid, viven en pareja o casadas, con hijos, clase alta, trabajan, 40-49 años)

«-Después, cuando no haya niños, no haya gente para cubrir esos trabajos... tendrán que volver a tener ni...

-Ahora no nacen niños porque no se puede.» (GD Bilbao, viven en pareja o casadas, con hijos, clase baja, trabajan, 20-29 años)

Las mujeres en situación de monoparentalidad elaboran un discurso acerca de la mujer autosuficiente, que no necesita, no necesitará en el futuro, a los hombres. Se concibe incluso un modelo familiar basado en una madre con sus hijos, es decir, la monoparentalidad conscientemente elegida, quizá proyección gratificante de su propia situación.

«Yo no sé si el día de mañana pues se vivirá así [...] las mujeres con sus hijos y si tienen capacidad de vivir solas, es que no lo sé, eso es aventurar mucho en un futuro muy lejano, no lo sé. Pero, pero, pues eso, en plan leona, como las leonas en la selva, sí es verdad [...]. No hacen falta maridos, no, no, no, claro, por eso ahí está, yo es lo que digo, como las leonas con sus cachorros y cuando los cachorros se independizan la leona sigue su vida por ahí cazando y el león está ahí tumbado debajo del árbol y las leonas cazando...» (EP Madrid, monoparental, clase media, trabaja)

\section{RELACIÓN, INTERCAMBIO Y RECIPROCIDAD}

A pesar de las escasas referencias a prácticas colectivas en torno a los problemas que experimentan hoy las mujeres hay una fuerte conciencia en los discursos de las madres trabajadoras de pertenencia a un grupo social en proceso de cambio, proceso imparable hacia una situación mejor en la que ningún espacio les estará vetado. Se perciben como protagonistas de un proceso en el que con su acción están venciendo la resistencia masculina y transformando su posición en la sociedad.

«Tengo clarísimo que nada las parará [a las mujeres].»( EP Madrid, casada, clase alta, trabaja, 40-40 años)

«No tienen más remedio que aceptar que cada vez hay más mujeres en todos los sitios.» (EP Valencia, casada, clase media, trabaja, 40-40 años)

Se trata, además, de un proceso colectivo del que se sienten parte y que conecta a las mujeres de ahora con las de otras épocas que iniciaron el camino y también con las generaciones más jóvenes. Ello explica por qué cuando las madres trabajadoras de hoy dicen que no son y no quieren ser como sus madres ello no supone un conflicto ni por la falta de modelo de aquéllas ni por el deseo 
de perpetuación de éstas. Unas y otras se perciben próximas, a pesar de ser tan diferentes, como si recorrieran un camino común hacia el mismo objetivo.

Hay una implicación activa e importante de la generación de las abuelas en el avance laboral y profesional de las madres

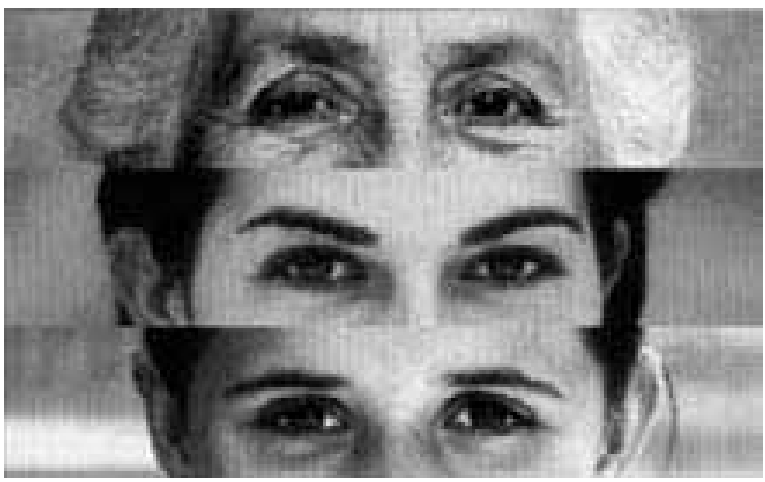
trabajadoras. La contradicción entre el nuevo rol laboral y el viejo rol familiar se resuelve o se aminora en muchos casos a través de la ayuda de la generación de las abuelas que se hacen cargo del cuidado de los nietos cuyas madres, sus hijas, trabajan.

«-¿Quién cuida a vuestros hijos cuando estáis trabajando?

-Mi madre.

-A mí mi madre.

-A mí mi madre.

-Las abuelas, ¿no?

-Mi hermana.»

(GD Madrid, viven en pareja o casadas, con hijos, clase baja, trabajan, 20-29 años)

«Si no fuera por mi madre me quedaría muy, muy colgada.» (EP Madrid, casada, con hijos, clase media, trabaja, 30-39 años)

"Cuando falten las abuelas no sé que será de nosotros» (EP Bilbao, casada, con hijos, clase baja, trabaja, 20-29 años)

En otros casos aunque la abuela no se encargue diariamente del cuidado de los hijos es la persona a la que se recurre en situaciones extraordinarias como enfermedades, vacaciones escolares o cuando la persona que habitualmente cuida de los niños no está disponible. La ayuda de la familia de origen y en especial de la abuela se intensifica en el caso de las mujeres en situación de monoparentalidad, hasta el punto de que frecuentemente es condición necesaria para la viabilidad de este tipo de familias.

«Ella sabe [la madre] que es la única a la que puedo pedir ayuda [...]. Claro, si no tuviera a mi madre no podrías hacer nada.» (EP Madrid, monoparental, clase baja, trabaja)

Ayuda intensa y necesaria, por tanto, que la primera generación de madres trabajadoras recibe de la generación anterior. Los fuertes vínculos familiares entre madres e hijas, rasgo típico de la familia tradicional, juegan un papel decisivo en nuestro país en la incorporación de la mujeres al trabajo remunerado, 
situación nueva para las mujeres que transformará, ya está transformando, la familia tradicional. Sin embargo, cuando se pregunta a las madres trabajadoras que hoy están siendo ayudadas por sus propias madres si asumirán ese mismo papel respecto a sus hijas trabajadoras en el futuro la respuesta es que no. Las nuevas generaciones, sus propias hijas, no podrán contar con las abuelas.

«-Pues guardería al canto, porque las abuelas esteremos trabajando.

-No me quedaré, por supuesto, con mi nieto. Eso lo tengo muy claro.

-Hombre, yo pienso que por hobby no. O sea, porque mi hija gane más, tenga mejor vida, no. Pues para que la tenga ella, la tengo yo... que también he pasado lo mío.» (GD Madrid, viven en pareja o casadas, con hijos, clase baja, trabajan, 20-29 años)

«Hoy llamamos a nuestras madres cuando el niño se nos pone malo, ya veremos si nuestras hijas nos van a llamar a nosotras, porque me parece que nosotras...» (GD Madrid, viven en pareja o casadas, con hijos, clase media, trabajan, 30-39 años)

"Yo no dejaré mi trabajo por cuidar los hijos de mi hija.» (EP Madrid, casada, con hijos, clase media, trabaja, 30-39 años)

\section{CONCLUSIÓN: MÁS ALLÁ DE LA RECIPROCIDAD, SOLIDARIDAD}

La reciprocidad constituye una forma de intercambio diferido que crea o fortalece el vínculo social. Es la lógica del don la que subyace ${ }^{10}$. Dar es una obligación, así como recibir y devolver. Reciprocidad e intercambio difieren. Éste implica simultaneidad, por lo que la relación social entre el que da y el que recibe se reduce a un momento, o a una sucesión de momentos. La reciprocidad supone, fundamentalmente, que hay obligación de dar y derecho a recibir en el futuro: el que da y el que recibe quedan fuertemente vinculados. La reciprocidad supone también que lo que se da y lo que se recibe es más o menos similar, aunque no exactamente equivalente como en el intercambio. Formas de reciprocidad entre tres generaciones a través de la generación intermedia han existido a lo largo de la historia, en ocasiones concretadas en transferencias monetarias o de servicios entre abuelos y nietos ${ }^{11}$. La solidaridad es un concepto próximo que va más allá de la reciprocidad y no supone necesariamente la obligación de dar a cambio ${ }^{12}$. En algunos casos, en algunos momentos históricos, una generación puede dar más de lo que previsiblemente recibirá o, por el contrario, recibir más de lo que ha dado o dará. Este parece ser el caso de la ayuda que la última generación de mujeres amas de casa da a la primera generación de madres trabajadoras en nuestro país.

10. Mauss, M.: Sociologie et Anthropologie, Presses Universitaires de France, París, 1950, pp. 155-268.

11. §GALEN, M.: "Continuités et discontinuités familiales: approche socio-historique du lien intergénérationnel», en Claudine Attias-Donfut (ed.): Les solidarités entre générations. Vieillesse, Familles, État, Nathan, París, 1995, pp. 27-40.

12. Attias-Donfut, Claudine (ed.): op.cit., pp. 5-23. 
El concepto de "cuidado social»13 elaborado por Mary Daly y Jane Lewis ${ }^{14}$ ayuda a entender la relación de ayuda entre generaciones de mujeres. El cuidado es el resultado de la combinación de recursos procedentes de la familia, el Estado y el mercado. En todos los países europeos, así como en otros muchos, estos tres elementos están presentes, pero el peso relativo de cada uno de ellos varía mucho. En los países del sur de Europa, y particularmente en España, el recurso principal es la familia, cuya importancia paradójicamente se acrecienta, en un momento de cambio social como el que hoy experimentamos.

No hay en el discurso de las madres trabajadoras complejo de culpa ni idea de reciprocidad entre generaciones, de que deban dar a la siguiente generación la ayuda que hoy están recibiendo de la precedente. Ello se explica seguramente porque se consideran diferentes, se consideran como una generación de transición que tiene que recurrir a soluciones de urgencia, a estrategias provisionales, como la solidaridad y ayuda de sus propias madres, soluciones que no constituyen un modelo de futuro.

Así, la última generación de mujeres mayoritariamente amas de casa, la generación de las abuelas duplica su rol de madre, primero cuidando a sus propios hijos, después a sus nietos. En cambio la primera generación de madre trabajadoras no reproducirá, o al menos eso creen hoy, el rol de abuela cuidadora con sus futuros nietos, modificándose y reduciéndose los intercambios entre generaciones. La última generación representante del viejo rol doméstico femenino, la de las abuelas, ejerce una doble solidaridad generacional, cuidando a sus hijos y a sus nietos. La primera generación representante del nuevo rol laboral femenino recibe una doble ayuda, primero a través de la socialización primaria de sí mismas, después a través del cuidado de sus hijos. Entre una y otra el intercambio no es equivalente ni tampoco parece que se vaya a retomar la reciprocidad de los intercambios con la siguiente generación de las más jóvenes. El ciclo se cierra y lo que era un asunto de mujeres emerge como nuevo problema social que a todos concierne.

\section{BIBLIOGRAFÍA}

AtTias-Donfut, Claudine (ed.): Les solidarités entre générations. Vieillesse, Familles, État, Nathan, París, 1995.

Cruz Cantero, P.: Percepción social de la familia en España, Centro de Investigaciones Sociológicas, 1995.

Daly, Mary y LewIS, Jane: «Introduction. Conceptualising Social Care in the Context of Welfare State Restructuring», en Jane Lewis (ed.): Gender, Social care and Welfare State Restructuring in Europe, Ashgate, Aldershot, 1999.

- "The concept of social care and the analysis of contemporary welfare states», The British Journal of Sociology, 51 (2000), pp. 281-298.

13. El término original es «social care».

14. Daly, Mary y LeWIS, Jane: «Introduction. Conceptualising Social Care in the Context of Welfare State Restructuring", en Jane Lewis (ed.): Gender, Social care and Welfare State Restructuring in Europe, Ashgate, Aldershot, 1999 y de las mismas autoras «The concept of social care and the analysis of contemporary welfare states», The British Journal of Sociology, 51 (2000), pp. 281-298. 
Fernández Cordón, J.A. y Tobío, C.: «Las Familias monoparentales en España», Departamento de Humanidades, Ciencia Política y Sociología, Informe de investigación realizada mediante convenio con el Ministerio de Asuntos Sociales, 1997.

GIDDENS, Anthony: La transformación de la intimidad. Sexualidad, amor y erotismo en las sociedades modernas, Cátedra, Madrid, 1995.

Instituto Nacional de Estadística: Censo de Población de 1991. Tomo I. Resultados Nacionales, Características Generales de la Población, Madrid, 1994.

Martínez Quintana, M.V.: Mujer, trabajo y maternidad. Problemas y alternativas de las madres que trabajan, Instituto de la Mujer, Ministerio de Asuntos Sociales, Madrid, 1992.

Mauss, M.: Sociologie et Anthropologie, Presses Universitaires de France, París, 1950.

SeGAlen, M.: "Continuités et discontinuités familiales: approche socio-historique du lien intergénérationnel», en Claudine Attias-Donfut: Les solidarités entre générations. Vieillesse, Familles, État, Nathan, París, 1995, pp. 27-40.

Rodríguez Rodríguez, P. y Sancho CAstiello, M.T.: «Vejez y familia: apuntes sobre una contribución desconocida», Infancia y Sociedad, 29 (1995), pp. 63-78.

Tobío, C.; Arteta, E. y Fernández Cordón, J.A.: «Estrategias de compatibilización familia-empleo. España años noventa». Departamento de Humanidades, Ciencia Política y Sociología, Universidad Carlos III de Madrid/ Instituto de la Mujer, Informe de Investigación, 1996.

Tobío, C.; Sampedro, R. y Montero, M.: "Obstáculos para la incorporación de las mujeres a la actividad laboral en la periferia rural y metropolitana de la Comunidad de Madrid». Departamento de Humanidades, Ciencia Política y Sociología, Informe de la investigación realizada mediante convenio con la Dirección General de la Mujer de la Comunidad de Madrid, 1997. 